\title{
ANÁLISE DO EQUILIBRIO LÍQUIDO-VAPOR DO SISTEMA ETANOL-ÁGUA NA PRESENÇA DE SAIS E DOIS LÍQUIDOS IÔNICOS A PRESSÃO ATMOSFERICA.
}

\author{
L. V. A. JURADO ${ }^{1}$, C. S. SILVA ${ }^{1}$ e M. F. MENDES ${ }^{1}$ \\ ${ }^{1}$ Universidade Federal Rural do Rio de Janeiro, Departamento de Engenharia Química \\ E-mail para contato: marisamf@ufrrj.br
}

\begin{abstract}
RESUMO - Este trabalho visa a comparação dos dados experimentais de equilíbrio líquido-vapor do sistema binário etanol-água, na presença de dois sais e dois líquidos iônicos diferentes, à pressão atmosférica. Vários solventes vêm sendo testados nesse sistema, entre eles se destacam os solventes orgânicos (benzeno, etilenoglicol, etc.), sais ( $\mathrm{NaCl}$, acetatos de sódio e potássio) e líquidos iônicos (LI's). Apesar do aumento dos estudos envolvendo o sistema etanol-água e da procura por agentes de separação cada vez mais eficientes, ainda existe uma escassez de dados na literatura, que são fundamentais para o projeto e síntese dos processos de separação. Os solventes escolhidos neste trabalho foram dois sais (acetato de sódio e nitrato de cálcio) e dois líquidos iônicos (EMISE-1-etil-3-metil imidazólio sulfeto e [EMIM][CL]-1-etil-3-metilimidazóliocloreto). Os dados foram medidos usando-se um ebuliômetro do tipo Othmer e as análises de composição foram feitas através de um densímetro digital. Todos os experimentos foram realizados em triplicata e a fração mássica dos sais usada foi 0,06 mol. $\mathrm{L}^{-1} \mathrm{e}$ de líquido iônico foi de $10 \%(\mathrm{~m} / \mathrm{m})$. Este estudo mostrou que todos os solventes utilizados foram eficientes no enriquecimento do etanol na fase vapor. $\mathrm{O}$ acetato de sódio e o EMISE conseguiram "quebrar" o azeótropo, enquanto o nitrato de cálcio e o [EMIM][CL] só o deslocaram.
\end{abstract}

\section{INTRODUÇÃO}

Com o constante crescimento da demanda de energia do mundo levou-se a um aumento do preço do petróleo bruto, influenciando diretamente nas atividades econômicas globais. A partir desse aumento foi necessária a procura por fonte de energias alternativas que visam serem renováveis, sustentáveis, com menor custo e menor impacto ambiental. Entre algumas dessas energias ganha destaque a produção de biocombustíveis (NIGAM et al. , 2011). Um deles é o etanol que vem sendo cada vez mais utilizado como combustível automotivo (etanol hidratado) ou em misturas à gasolina (etanol desidratado) e, atualmente, o Brasil se encontra no ranking mundial como um dos maiores produtores (MATUGI, 2013)

O etanol possui diversas utilidades na indústria como reagente em diversas reações químicas (produção de biodiesel) ou para uso doméstico (RAVAGNANI et al., 2010 apud SOARES, 2010). Um dos seus principais usos é na área de combustíveis, como auxiliar na gasolina já que consegue promover um aumento do número de octanagem, gerando uma 
queima superior do combustível, o que leva a uma redução das emissões de monóxido de carbono e particulados na atmosfera. Porém para que esse processo seja possível, o etanol precisa estar isento de agua, ou seja, desidratado entre uma composição de 99,3 e 99,8\% em massa de etanol, se não ele acaba formando duas fases quando misturado à gasolina gerando problemas no motor (GOMIS et al., 2006).

Para conseguir a pureza necessária do etanol, é realizada a separação da mistura etanolágua, com a adição de um agente separador que seja capaz de modificar o equilíbrio líquidovapor. Este processo de separação é conhecido como destilação extrativa ou azeotrópica, dependendo da volatilidade da substância (SILVA, 2016). Vários estudos vêm sendo realizados ao longo dos anos propondo diferentes agentes de separação, sempre buscando processos mais limpos e eficientes (SOUZA, 2012).

Os sais são alguns dos solventes estudados, por serem efetivos na modificação desse equilíbrio líquido-vapor da mistura etanol-água e pelo fato de não serem voláteis, consumindo menos energia ao longo do processo e por possuírem baixo custo se comparado com outros solventes. Esta é uma importante característica nos dias atuais (SOARES, 2010).

Outro agente de separação é o líquido iônico, que ganha cada vez mais destaque devido às características físico-químicas, como ponto de fusão inferior a $100{ }^{\circ} \mathrm{C}$, pressão de vapor baixa, são estáveis térmica e quimicamente e, em geral, não são voláteis e nem corrosivos (SILVA, 2016).

Diante do exposto, esse trabalho tem como objetivo a medida experimental de novos dados de equilíbrio do sistema etanol-água envolvendo dois sais (acetato de sódio e nitrato de sódio) e dois líquidos iônicos (1-etil-3-metil-imidazólio Sulfeto (EMISE) e o 1-etil-3-metilimidazólio cloreto [EMIM][CL]). Com isso, a influência dos mesmos na recuperação do etanol poderá ser comparada.

\section{MATERIAIS E MÉTODOS}

\subsection{Materiais}

Acetato de Sódio Anidro (Vetec Química Fina Ltda), Nitrato de Cálcio tetra-hidratado (Vetec Química Fina Ltda), 1-etil-3-metil-imidazólio cloreto (Siga-Aldrich), 1-etil-3-metilimidazólio Sulfeto (Siga-Aldrich), Álcool Etílico Absoluto (99,8\% de pureza, ISOFAR Market) e água destilada foram usados para realizar os experimentos.

\subsection{Metodologia Experimental}

Os dados experimentais foram medidos em triplicata usando misturas de água-etanol em frações molares variando entre 0,2 a 0,95 de etanol. Já os sais foram utilizados na proporção de 0,06 mol. $\mathrm{L}^{-1}$ e os líquidos iônicos na concentração de $10 \%(\mathrm{~m} / \mathrm{m})$.

Esses valores de concentração e de frações mássicas foram escolhidos visando dar continuidade e comparar com trabalhos já realizados pelo mesmo grupo de pesquisa nas 
mesmas proporções ou com trabalhos já publicados na literatura, porém usando outros solventes.

Para a medida dos dados de equilíbrio líquido-vapor foi utilizado um ebuliômetro semelhante ao de Othmer apresentado na Figura 1, a pressão atmosférica, com refluxo total, com dois condensadores e capacidade de $300 \mathrm{~mL}$. Este ebuliômetro foi testado em outros sistemas estudados anteriormente (benzeno-tolueno, benzeno-heptano, etanol-água-glicerol e projetado, no próprio laboratório (SOUZA et al., 2013).

O procedimento experimental inicia com a pesagem das massas, estipuladas de acordo com a fração molar dos componentes da mistura água-etanol e da concentração dos solventes. A carga é introduzida na célula de equilíbrio com pequenas esferas de vidro e um agitador magnético. O sistema isolado é posto sob agitação durante 5 minutos e, após este, o aquecimento do sistema é iniciado pela placa de aquecimento.

Figura 1 - Representação esquemática do ebuliômetro, com (A) medição de temperatura da fase líquida, (B) célula de equilíbrio, (C) condensador secundário, (D) condensador primário,

(E) saída para amostragem da fase vapor, (F) saída para o ar atmosférico, (G) medição de temperatura da fase vapor (Adaptado de Souza et al., 2013).

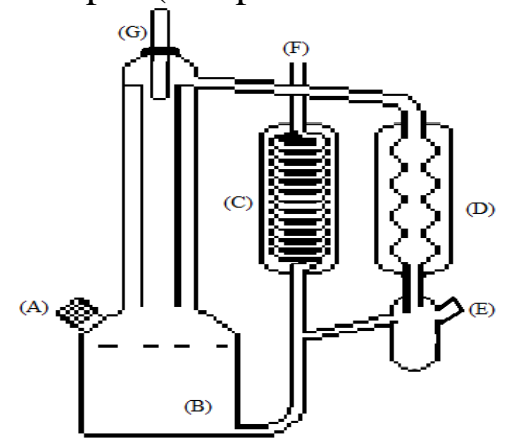

A temperatura do ponto de bolha foi monitorada em intervalos de 10 minutos, com um termopar $\left( \pm 0,01{ }^{\circ} \mathrm{C}\right)$ e, após a mesma permanecer constante durante 30 minutos, admite-se que o equilíbrio foi estabelecido. As amostras da fase vapor são recolhidas, ainda com o fluxo de água e o aquecimento ocorrendo garantindo o equilíbrio, e analisadas em um densímetro digital (Gehaka, DSL 920). Todos os experimentos foram realizados em triplicata

\subsection{Análises das Amostras}

A concentração das amostras oriundas do equilíbrio líquido-vapor foi analisada através de um densímetro digital (Gehaka, DSL 920, $\pm 10^{-5} \mathrm{~g} / \mathrm{cm}^{3}$ ), que utiliza o método gravimétrico para a medição. A partir da densidade das amostras, a concentração foi obtida através de uma curva de calibração, que descreve a variação da densidade por toda a faixa de concentração do sistema etanol-água. 


\section{RESULTADOS E DISCUSSÕES}

Na Tabela 1 são apresentados os resultados de temperatura e composição da fase vapor, que são as médias das triplicatas obtidas experimentalmente para o acetato de sódio e nitrato de cálcio na fração de 0,06 mol. $\mathrm{L}^{-1}$, com seus respectivos desvios padrão. Os dados experimentais são apresentados na Figura 2, onde pode ser observado a "quebra" do azeótropo para o acetato de sódio e, para o nitrato de sódio, só pode ser observado o deslocamento do azeótropo, enriquecendo o etanol na fase vapor. Para fins de comparação, na Figura 2 também é apresentado a curva de equilíbrio do sistema binário etanol-água (DECHEMA, 1981), para melhor observação da "quebra"ou deslocamento do azeótropo.

O mesmo comportamento foi observado para os dois líquidos iônicos, utilizados na fração mássica de $10 \%$. Os dados de equilíbrio podem ser observados na Tabela 2 e a Figura 3 mostra o comportamento quanto à "quebra" e/ou deslocamento do azeótropo. Pode-se perceber que o EMISE conseguiu "quebrar" o azeótropo, enquanto o [EMIM][CL] só conseguiu deslocar o mesmo, garantindo um enriquecimento na fase vapor de etanol.

Tabela 1 - Dados de Equilíbrio Líquido-Vapor do sistema etanol-água-sal obtidos experimentalmente a pressão atmosférica

\begin{tabular}{|c|c|c|c|c|c|c|c|c|}
\hline \multirow{2}{*}{$\mathrm{X}_{\text {etanol }}$} & \multicolumn{4}{|c|}{ Acetato de Sódio } & \multicolumn{4}{c|}{ Nitrato de Cálcio } \\
\cline { 2 - 9 } & $\mathrm{y}_{\text {etanol }}$ & $\mathrm{T} / \mathrm{K}$ & $\mathrm{DP} * \mathrm{y}$ & $\mathrm{DP} * \mathrm{~T}$ & yetanol & $\mathrm{T} / \mathrm{K}$ & DP*y & DP*T \\
\hline 0,2 & 0,6813 & 354,03 & $9,11 \mathrm{E}^{-04}$ & $4,72 \mathrm{E}^{-02}$ & 0,7808 & 354,92 & $2,87 \mathrm{E}^{-02}$ & $5,73 \mathrm{E}^{-01}$ \\
\hline 0,4 & 0,7713 & 353,94 & $3,10 \mathrm{E}^{-03}$ & $1,47 \mathrm{E}^{-01}$ & 0,8370 & 353,95 & $2,00 \mathrm{E}^{-02}$ & $4,50 \mathrm{E}^{-01}$ \\
\hline 0,6 & 0,7936 & 352,59 & $1,77 \mathrm{E}^{-03}$ & $2,62 \mathrm{E}^{-02}$ & 0,8802 & 352,55 & $9,04 \mathrm{E}^{-03}$ & $1,63 \mathrm{E}^{-01}$ \\
\hline 0,8 & 0,9132 & 351,60 & $8,22 \mathrm{E}^{-04}$ & $2,36 \mathrm{E}^{-02}$ & 0,9926 & 352,12 & $1,62 \mathrm{E}^{-02}$ & $4,71 \mathrm{E}^{-02}$ \\
\hline 0,9 & 0,9476 & 351,48 & $6,58 \mathrm{E}^{-04}$ & $5,10 \mathrm{E}^{-02}$ & 0,9991 & 351,22 & $2,89 \mathrm{E}^{-03}$ & $4,71 \mathrm{E}^{-01}$ \\
\hline 0,95 & 0,9480 & 351,52 & $4,41 \mathrm{E}^{-03}$ & $2,16 \mathrm{E}^{-02}$ & 0,9909 & 348,02 & $8,50 \mathrm{E}^{-03}$ & $4,71 \mathrm{E}^{-02}$ \\
\hline
\end{tabular}

*DP - desvio padrão das medidas de composição e temperatura

Figura 3 - Dados de equilíbrio líquido-vapor do sistema ternário etanol-água-sal para os dois sais utilizados neste trabalho na fração molar de 0,06 mol. $\mathrm{L}^{-1}$.

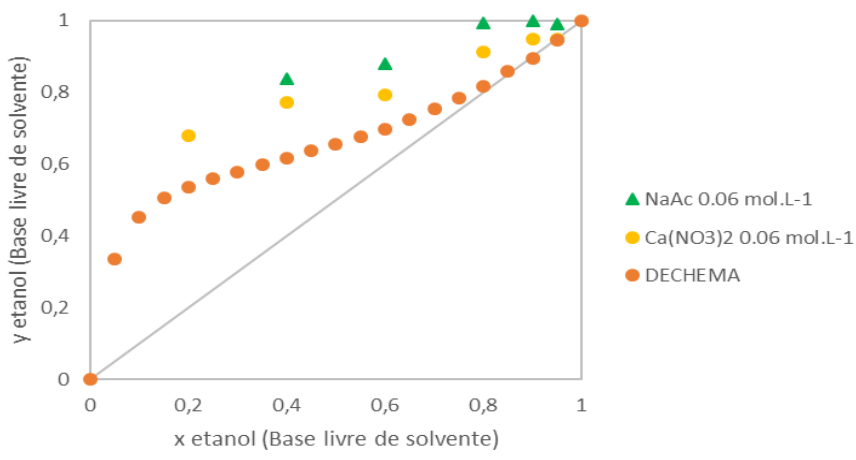




\section{C*B:BEO [201 \\ XII Congresso Brasileiro de Engenharia Química \\ em Iniciação Científica \\ UFSCar - São Carlos - SP

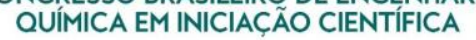 \\ 16 a 19 de Julho de 2017}

Tabela 2 - Dados de Equilíbrio Líquido-Vapor do sistema etanol-água-líquido iônico obtidos experimentalmente a pressão atmosférica

\begin{tabular}{|c|c|c|c|c|c|c|c|c|}
\hline \multirow{2}{*}{$\mathrm{X}_{\text {etanol }}$} & \multicolumn{4}{|c|}{ EMISE } & \multicolumn{4}{|c|}{ [EMIM][CL] } \\
\hline & yetanol & $\mathrm{T} / \mathrm{K}$ & $\mathrm{DP}^{*} \mathrm{y}$ & $\mathrm{DP} * \mathrm{~T}$ & Yetanol & $\mathrm{T} / \mathrm{K}$ & $\mathrm{DP}^{*} \mathrm{y}$ & $\mathrm{DP} * \mathrm{~T}$ \\
\hline 0,2 & 0,649 & 355,14 & $0,90 \mathrm{E}^{-02}$ & $4,00 \mathrm{E}^{-02}$ & 0,7699 & 354,61 & $2,06 \mathrm{E}^{-02}$ & $3,99 \mathrm{E}^{-01}$ \\
\hline 0,4 & 0,7261 & 352,88 & $0,93 \mathrm{E}^{-02}$ & $1,00 \mathrm{E}^{-02}$ & 0,8489 & 352,80 & $2,01 \mathrm{E}^{-03}$ & $8,96 \mathrm{E}^{-02}$ \\
\hline 0,6 & 0,7631 & 352,10 & $0,22 \mathrm{E}^{-02}$ & $0,96 \mathrm{E}^{-02}$ & 0,8578 & 352,25 & $6,91 \mathrm{E}^{-04}$ & $8,06 \mathrm{E}^{-02}$ \\
\hline 0,8 & 0,8363 & 351,47 & $0,52 \mathrm{E}^{-02}$ & $3,61 \mathrm{E}^{-02}$ & 0,9352 & 351,73 & $2,05 \mathrm{E}^{-03}$ & $1,25 \mathrm{E}^{-02}$ \\
\hline 0,9 & 0,854 & 351,36 & $0,51 \mathrm{E}^{-02}$ & $7,60 \mathrm{E}^{-02}$ & 0,9634 & 351,76 & $2,32 \mathrm{E}^{-03}$ & $2,45 \mathrm{E}^{-02}$ \\
\hline 0,95 & 0,9277 & 351,50 & $0,51 \mathrm{E}^{-02}$ & $6,50 \mathrm{E}^{-02}$ & 0,9866 & 351,75 & $9,77 \mathrm{E}^{-04}$ & $3,30 \mathrm{E}^{-02}$ \\
\hline
\end{tabular}

*DP - desvio padrão das medidas de composição e temperatura

Figura 4 - Dados de equilíbrio líquido-vapor do sistema ternário etanol-água-líquido iônico tanto para o EMISE como para o [EMIM][CL] na fração mássica de $10 \%$.

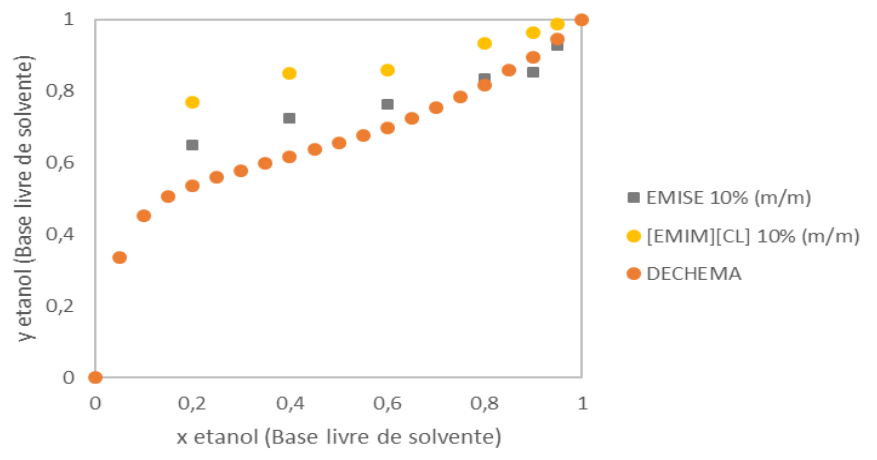

\section{CONCLUSÃO}

Neste trabalho, observou-se que os quatro solventes estudados foram eficazes no enriquecimento do etanol na fase vapor comportando-se de forma satisfatória, comprovando assim uma maior afinidade dos solventes com a água do que com o etanol. O efeito "salting out" foi observado em toda a curva de equilíbrio sob a influência dos sais e dos líquidos iônicos. Apesar disso, somente dois deles (acetato de sódio e o EMISE) conseguiram "quebrar" o azeótropo, possibilitando a obtenção de etanol desidratado. Já o nitrato de cálcio e o [EMIM][Cl], nas frações estudadas, não foram capazes de "quebrar" o azeótropo, mas provocaram um leve deslocamento, levando ao aumento da concentração de etanol na fase vapor. De forma geral, o acetato de sódio e o EMISE mostraram-se promissores a serem aplicados em colunas de destilação para a desidratação do etanol. 


\section{REFERENCIAS}

GOMIS V., FRONT A., SAQUETE M.D. Vapour - liquid - liquid and vapour - liquid equilibrium of the system water+ethanol+heptane at $101.3 \mathrm{kPa}$. Fluir Phase Equil., 248, p. 206-210, 2006.

GMEHLING, V. J.; ONKEN, U.; ARLT, W. Frankfurt/M. DECHEMA. VAPOR-LIQUID EQUILIBRIUM DATA COLLECTION, Aqueous-Organic Systems (Supplement 1), v. 1, part 1a, 1981

LEAL, C. Equilíbrio líquido-vapor para sistema ternário etanol-água-líquido iônico. 2015. Dissertação (Mestrado em Engenharia Química, Tecnologia Química). Instituto de Tecnologia, Departamento de Engenharia Química, Universidade Federal Rural do Rio de Janeiro, Seropédica, RJ.

MATUGI, K. Produção de etanol anidro por destilação extrativa utilizando soluções salinas e glicerol. 2013. Dissertação (Mestrado em Engenharia Química). Universidade Federal de São Carlos, 2013.

NIGAM, P.; SINGH, A. Production of liquid biofuels from renewable resources. Progress in Energy and Combustion Science, v. 37, p. 52-68, 2011.

SILVA, C. S. Equilíbrio líquido-vapor do sistema ternário etanol + água + 1-etil-3-metil imidazólio cloreto: experimental e modelagem termodinâmica. Dissertação (Mestrado em Engenharia Química, Processos Químicos). Instituto de Tecnologia, Departamento de Engenharia Química, Universidade Federal Rural do Rio de Janeiro, Seropédica, RJ, 2016.

SOARES, R. B. Estudo da destilação extrativa salina em coluna recheada para a produção de etanol. Tese de Mestrado. 2010. 98f. Dissertação em Engenharia Química - Instituto de Tecnologia, Universidade Federal Rural do Rio de Janeiro, Seropédica.

SOUZA, W L. R.; SILVA, C. S.; MELEIRO, L. A. C.; MENDES, M. F. Vapor-liquid equilibrium of the (water + ethanol + glycerol) system: Experimental and modelling data at normal pressure. J. Chem. Thermodynamics, v. 67, p. 106-111, 2013. 